\title{
The Dense Use of Lexicalization in Dialogues by EFL Students at Jordan University-Aqaba
}

\author{
Abdel-Hameed Al-Awabdeh, Ibrahem Bani Abdo \\ Department of English Language and Literature, Faculty of Foreign Languages, University of Jordan, Aqaba, Jordan \\ Email: ibrahim_re@yahoo.com,drhamedluna79@gmail.com
}

How to cite this paper: Al-Awabdeh, A.-H., \& Abdo, I. B. (2017). The Dense Use of Lexicalization in Dialogues by EFL Students at Jordan University-Aqaba. Creative Education, 8, 671-677. https://doi.org/10.4236/ce.2017.85052

Received: October 15, 2016

Accepted: December 1, 2016 Published: April 30, 2017

Copyright $\odot 2017$ by authors and Scientific Research Publishing Inc. This work is licensed under the Creative Commons Attribution International License (CC BY 4.0).

http://creativecommons.org/licenses/by/4.0/ cc) (i) Open Access

\begin{abstract}
This qualitative and quantitative analysis, researching language and social interaction, is one of its kinds, to examine the current ESL pedagogical strategies in native and residential Jordanian college students. It uses lexicalization in spoken dialogues produced by English language and literature students at the Department of English Language and Literature at Jordan University/Aqaba branch. It includes 30 participants selected randomly. The study uses Hoey's (1991) Matrix of Lexical Cohesion and a Semi-structured Interview to collect data from the participants. The findings indicated that the density of lexicalization has a significant contribution in the creation of cohesion of the spoken dialogues. This research recommends that further research be conducted to investigate other types of spoken dialogues
\end{abstract}

\section{Keywords}

Discourse Analysis, Oral skills, Dialogues, Lexicalization, Cohesion

\section{Introduction}

The recent studies of spoken dialogue have tendencies to prevent interaction patterns to simple language exchanges with the language users (speaker/listener). Dialogues are restricted to a sentence level not like natural human interaction. Language users are restricted to flexibility of turn-taking conversation and shifting beyond the sentence level requires a deep understanding of the scenery of the spoken dialogue. This kind of shifting is significant and an adequate starts to construct the main blocks of speech production. Speakers are expected to implement and adequate convention actively in a proper manner (McBurney \& Parsons, 2002)

Utterances rather sentences are the basic blocks of any scientific research and the act of speech is the primary concern of spoken dialogue in varied shapes and forms. Therefore, the different types of sentences are exclusively studied by DA 
(discourse analysis) rather than the inner connections of the different types of sentences. Consequently, discourse analysis focuses on interlinking between the bits of speech in any dialogue. Providing an adequate definition of utterances units serves on how to find the differences between the utterances' internal language processes such as speech repairs and phonology from the function of discourse level as in the rhetorical function and turn taking (Lewis, 2009). Consequently, the discoursal function of dialogues' utterances is the main interest of this paper.

This study is targeting 1) turn interaction and 2) the interactions the collaborative works of the speakers. The speech dialogues are analysed at discourse level where successful installments related to prospective boundary signals are used by speakers. This study gives some insights, observations, and elaborations of the implications for spoken dialogue systems at discourse level (Henry, 2006).

\section{Statement of the Problem}

English is considered to be as one of the most widespread languages in the world which is highly used for communicative purpose. Despite, English is generally integrated into Jordanian education and culture because of business, political, and touristic-related demands from international, interactive populations, used as foreign language (EFL), most college students or even graduated ones have difficulties when attempting to produce an utterance or speech (Bani Abdo \& Breen, 2010). Although these college English major students have accomplished many oral courses, they are unable to produce a connected speech (Al Khotaba, 2010).

The research study presented here aims at exploring the significance of lexicalization to English Language and Literature students in a Jordanian context at university level.

\section{Objectives of the Study}

This research objective aims to elicit data on the use of lexicalization in spoken dialogues created by B.A students at the Department of English Language and Literature at Aqaba Jordan University. As a result, this study aims to achieve the following objectives.

To investigate how lexical repetitions promote the creation of lexicalization in spoken dialogues.

To examine how lexicalization promotes the cohesion of the spoken dialogues.

\section{Research Questions}

Q1: How lexical repetitions contribute to the creation of lexicalization in spoken dialogues?

Q2: Does lexicalization develop the cohesion of the spoken dialogues?

\section{Review of Literature}

Speaking is one of the most important aspects in English language learning. 
Many Jordanian students in EFL programs also suffer in acquiring the English language because they oftentimes feel that the language itself is not a necessity; some of them feel it is not a practical tool that they'll use in the future for employment or communication purposes. This attitude is actually a misconception at times, because English does become an important language, especially in Amman the country's capital and Aqaba where it considers a tourists' city, where international business and communication take place (Skinner \& Brown, 2003; Joffe, 2002). "Of course, not all Jordanian citizens choose to live in regions of the country where English is spoken or used. Hence, it depends on the ambitions of the individual students and whether these individuals desire to venture into occupations or situations that will require a proficient or functional level of English understanding, including oral and written communication skills" (Bani Abdo \& Breen, 2010). Speaking is a way to exchange feelings, emotions, and demands. It is not only a matter of putting utterances together, but it is also an issue of being one of the most significant aspects that is very confusing to master in the learning process (Ahmed, 2010). Chakraverty and Gautum (2000) state that speaking skill is used to convey meaning of spoken words through a set of signs and symbols between a speaker and a hearer. Knowing the structure of a language, organization of ideas and thoughts of that language are also crucial element to master the skill learning and acquiring.

Speaking is a linguistic tool that is used by the writer to express ideas within a specific culture and is one of the four basic skills to master a language in a dialogue (Zughoul, 1991). A dialogue is a spoken conversational exchange between two or more people (Prakken \& Sartor, 2006). There are three main stages of exchanging conversation. The first is the opening stage where speaker and hearer should be involved in a dialogue as a collective work (Walton \& Krabbe, 1995). This stage involves the different types of dialogue, the dialogue's goal, the initial situation, the participants, and the participant's goals. The second stage is the argumentation stage. This stage applies a global burden of proof (Gordon \& Walton, 2009). The third stage is the closing one which refers to the successfulness or not of the dialogue (Walton, 1998). Other scholars such as McBurney and Parsons (2002) have classified dialogues into seven basic types as "persuasion", "inquiry", "discovery", "negotiation", "information-seeking", "deliberation" and "Eristic".

\section{Method}

This study is a qualitative and quantitative analysis researching the density of lexicalization in spoken dialogues created by 30 English and literature students. The study is conducted at the Department of English Language and Literature at Jordan University in Aqaba. The Jordanian participants were randomly chosen from University of Jordan of different gender and aged between 18 - 25 years old. The spoken dialogues have been collected by the fall academic semester of 2016.

The instrument used in this paper involves 1) a semi-Structured Interview, 
and 2) Hoey's (1991) Matrix of Lexical Cohesion. Recently, easily accessible and powerful computer software has renewed the interest in quantitative study in linguistics and there is even a developing sub-discipline increasingly referred to discourse analysis (Jeffries \& McIntyre, 2010). Consequently, the quantitative analysis used in this study seek to understand a phenomenon more fully than is possible using either quantitative or qualitative method alone (Gay et al., 2009: p. 462).

This quantitative and qualitative analysis investigates the use of lexicalization of English literature students to gain a deeper insight and understanding of the lexicalization use in dialogues thereto express solidarity and meaningfulness. Subsequently, a semi-structured interview is conducted with one Linguist to triangulate research questions based on the data elicited from the participants in the study using Hoey's (1991) Matrix of Lexical Cohesion.

The aim is to gain insight into the English language (oral skills) lecturer's perception about the density of lexicalization to the unity of spoken dialogues. Peer dialogues were carried out and students are encouraged to be part of these dialogues.

The sample of the study comprises 30 randomly chosen participants at the Department of English Language and Literature at Jordan University/Aqaba in Jordan for the fall semester of the academic year 2016/2017. All the students selected for the study are bilingual students (English and Arabic speakers) and all of them have B.A degree in English Language and literature. Arabic is their native language. They are of different gender and share the same ethnicity and background. The participants come from different cities and towns in Jordan. They are of similar ages ranging between $19-22$ years. The random sampling "is the best way to obtain a representative sample” (Gay \& Airasian, 2003: p. 183). The randomly chosen sample is considers as a representative sample to answer the research questions.

\section{Findings and Discussions}

This section provides a conclusion on the findings of this study which explores the dense use of lexicalization in the spoken dialogues and produced by the 30 English language and literature students at the Department of English Language and Literature at Jordan University/Aqaba.

The study found out that English language and literature were able to use the different types of lexical repetition (simple and complex repetition, simple and complex paraphrase, co-reference, substitution, ellipsis and conjunction) across the 15 spoken dialogues. Their use is also varied from one type of lexical repetition to another. The percentages of the use of these lexical repetition types ranged gradually from the first type of lexical repetition (simple lexical repetition) and recorded the highest percentage across the 15 spoken dialogues until the eighth type (Conjunction) that recorded the lowest percentage across these 15 dialogues.

The simple types of lexical repetition (simple lexical repetition and simple pa- 
raphrase) and complex lexical repetition were the highest percentages of occurrence The complex types (complex paraphrasing, co-reference, substitution, ellipsis and conjunction) scored low percentages through the dialogues. These scores indicated that students lack the needed vocabulary, inadequate use of spoken English, and incompatibility of the importance of using the different techniques and types of lexical repetitions in spoken dialogues.

The dense use of different types of lexical repetition enhances the cohesion and the unity of the spoken dialogues as McCarthy $(1991,1998)$ stated. The analysis of this study illustrates that the dense use of lexicalization of the students' speeches links sentences coherently in the same dialogue as it creates the non-linearity relations. Sentences were clearer in meaning than those which had a lower density of such repetitions.

Lexical links represent the connection between sentences and each lexical link is presented by three uses of lexical repetitions (Hoey, 1991). In this study, there were differences of the use lexicalization from one written dialogue to another depending on the emergence of the different kinds of lexical repetition. In this study, lexical links scored low percentage of 19\% throughout the 15 spoken dialogues. This percentage indicates that the given spoken dialogues were incoherent to some extent. This clarifies that the correlation between the occurrence of lexical link and the density of lexicalization reveals that the more the lexical links are found in a text the more the use of lexicalization and cohesion are. In addition, Hoey (1991) states that "lexical link" is regarded as a lexical bond as a sentence maintains three lexical links in a dialogue. The sentence which lacks three lexical links is considered insignificant as it possesses no lexical bondage with other sentences and it is called marginal sentence. As a result, this study concluded that the students were able to use a number of lexical links among their writings which creates lexical bonds of their written dialogues. These results of the dense and lack use of lexical repetition devices establishes lexical links that affect the overall cohesion of spoken dialogues.

This study also scored a low percentage of lexical bondage and the spoken dialogue scored a high percentage of marginal sentences. Nine spoken dialogues (D2, D3, D4, D6, D8, D10, D11, D12 and D13) were incoherent and have no central significant sentences as a result of low percentages of lexical links/bonds of the students' dialogues. On the other hand, dialogues (8) and (10) scored 70\% $85 \%$ of the lexically bonded sentences respectively.

According to Hoey (1991) and McCarthy (1991, 1998), the study findings revealed that the spoken dialogue that had many marginal sentences did not provide a meaningful summary to readers where spoken dialogue with a dense use of lexicalization and central sentences presented coherently and meaningfully. In addition, a written text which contained a low percentage of lexicalization, central sentence along with other lexically bonded sentences (Topic-opening and closing sentences) provided the readers with the central theme of the topic.

This study concludes the dense use of lexicalization affects the overall cohesion of the spoken dialogues. High percentages of lexicalization (central sen- 
tences and bonded ones) in written dialogues represent coherency and meaningfulness.

\section{Conclusions}

To conclude, lexicalizations keep dialogues coherent and ongoing. This study reveals that the students' sample had insufficient knowledge of lexical repetitions and lexicalization which affect the unity and continuity of their written dialogues. The semi-structured interview reveals that students (30) and instructors (two instructors at the English department) lack the awareness of the significance of lexicalization and lexical repetition concepts. They have to build a understanding of how lexicalization can create an overall cohesive in spoken dialogue.

These results may be limited because of the random sample size and might be better to expand the sample in the future studies. This study highlights of the nature of Jordanian English language and literature students' speeches and academic writing at Aqaba branch. It also benefits instructors of better strategies of teaching speeches and writing by using Hoey's and McCarthy concepts as an alternative method for teaching speaking and how to involve teaching lexicalization in their classes.

\section{References}

Ahmed, A. H. (2010). Students' Problems with Cohesion and Coherence in EFL Essay Writing in Egypt: Different Perspectives. Literacy Information and Computer Education Journal (LICEJ), 1, 214-221.

Al Khotaba, E. (2010). The Use of Lexical Repetition and Patterning in Written Compositions of Jordanian Students Majoring in English Language and Literature at Mu'tah University: A Case Study. Ph.D. Thesis. Malaysia: University Sains Malaysia.

Bani Abdo, I., \& Breen, G. (2010). Teaching EFL to Jordanian Students: New Strategies for Enhancing English Acquisition in a Distinct Middle Eastern Student Population. Creative Education, 1, 39-50. https://doi.org/10.4236/ce.2010.11007

Chakraverty, A., \& Gautum, K. (2000). Dynamics of Writing. Forum, 38, 40-55.

Gay, L. et al. (2009). Educational Research. Competencies for Analysis and Application (9th ed.). Pearson International Edition, Cambridge University Press.

Gay, L., \& Airasian, P. (2003). Educational Research: Competencies for Analysis and Application (7th ed.). Upper Saddle River, NJ: Pearson International Edition.

Gordon, T. F., \& Walton, D. (2009). Proof Burdens and Standards. In I. Rahwan, \& G. Simari (Eds.), Argumentation and Artificial Intelligence (pp. 239-260). Berlin: Springer. https://doi.org/10.1007/978-0-387-98197-0_12

Hoey, M. (1991). Patterns of Lexis in Text. Oxford: Oxford University Press.

Jeffries, L., \& McIntyre, D. (2010). Stylistics. Cambridge: Cambridge University Press.

Joffe, H. (2002). Jordan in Transition. Hampshire: Palgrave Macmillan.

Lewis, P. (2009). Ethnologue: Languages of the World (16th ed.). Dallas, TX: SIL International.

McBurney, P., \& Parsons, S. (2002). Dialogue Games in Multi-Agent Systems. Informal Logic. Special Issue on Applications of Argumentation in Computer Science, 22, 
257-274

McCarthy, M. (1991). Discourse Analysis for Language Teachers. Cambridge: Cambridge University Press.

McCarthy, M. (1998). Spoken Language \& Applied Linguistics. Cambridge: Cambridge University Press.

Prakken, H., \& Sartor, G. (2006). Presumptions and Burdens of Proof, Legal Knowledge and Information Systems: JURIX 2006. In The Nineteenth Annual Conference. Amsterdam: IOS Press.

Skinner, H., \& Brown, C. (2003). Jordan. Milwaukee: Gareth Stevens Publishing.

Walton, D. (1998). The New Dialectic: Conversational Contexts of Argument. Toronto: University of Toronto Press.

Zughoul, M. (1991). Lexical Choice: Towards Writing Problematic Word Lists. IRAL, 29, 45-60.

Submit or recommend next manuscript to SCIRP and we will provide best service for you:

Accepting pre-submission inquiries through Email, Facebook, LinkedIn, Twitter, etc. A wide selection of journals (inclusive of 9 subjects, more than 200 journals) Providing 24-hour high-quality service User-friendly online submission system Fair and swift peer-review system Efficient typesetting and proofreading procedure Display of the result of downloads and visits, as well as the number of cited articles Maximum dissemination of your research work

Submit your manuscript at: http://papersubmission.scirp.org/

Or contact ce@scirp.org 